\title{
Nursing care in Tuberculosis patients at a Spanish sanatorium, 1943-1975
}

Paola Galbany-Estragués ${ }^{2}$

Objectives: the objective in this study is to identify the profile of the nursing staff, the work conditions and to describe nursing care at a sanatorium located in Barcelona, Spain between 1943 and 1975. Method: historical study undertaken between 2008 and 2010, based on oral sources, five direct and one indirect testimonies, and the analysis of written documents. The data from the testimonies were collected through semistructured interviews. Results: the nursing staff, mostly religious women, had scarce material and economic resources and no preventive measures to take care of the ill. The nurses undertook activities centered on the basic needs for physical and spiritual wellbeing. Conclusion: The study reveals how the nurses, despite working in hostile conditions, attempted to safeguard the wellbeing of the patients and accompany them during the death process.

Descriptors: History of Nursing; Nursing; Tuberculosis; Spain.

\footnotetext{
${ }^{1}$ Paper extracted from doctoral dissertation "Evolution of nursing cares at the Hospital de I'Esperit Sant de Santa Coloma de Gramenet 1917-2010" presented to Escuela Universitaria de Enfermería, Universidad de Barcelona, Barcelona, Spain.

${ }^{2} \mathrm{PhD}$, Professor, Departamento de Enfermería, Universitat Autònoma de Barcelona, Barcelona, Spain.
}

Corresponding Author: Paola Galbany Estragués Universitat Autònoma de Barcelona. Departamento de Enfermería Despacho M3/210

Bellaterra (Cerdanyola del Vallès)

08193, Barcelona, España

E-mail: paola.galbany@uab.cat
Copyright (c) 2014 Revista Latino-Americana de Enfermagem This is an Open Access article distributed under the terms of the Creative Commons Attribution Non-Commercial License (CC BY-NC).

This license lets others distribute, remix, tweak, and build upon your work non-commercially, and although their new works must also acknowledge you and be non-commercial, they don't have to license their derivative works on the same terms. 


\section{Introduction}

Between the mid-19 $9^{\text {th }}$ and the mid-20 $0^{\text {th }}$ century, one of the most effective measures that existed to treat tuberculosis ( $\mathrm{Tb}$ ) was the patients' confinement in sanatoria(1). The first center was created in Gobersdorf (Silesia), in the German Alps, in 1854, on the initiative of the physician Herman Brehmer( ${ }^{(2)}$. Initially, the sanatoria were private centers with characteristics similar to luxury hotels, but later, in Europe and other parts of the world, public sanatoria were created to attend to poor tuberculosis patients ${ }^{(2-3)}$.

In the 19th century, the social class this disease most affected were the young workers from the industrial period who were victims of the hard living conditions(1). Tb was considered a social illness related to poverty, alcoholism, ignorance and immorality(4). Since then, tuberculosis, which had represented the consumptive beauty that was the symbol of romanticism(5), was considered a source of infection and danger to society $^{(6)}$ and turned into a stigmatized person ${ }^{(7)}$. To fight against the disease, countries from Latin America, Europe and the United States applied political public health measures and similar medical practices(3) Instead of improving the workers' living conditions, the campaigns against Tb centered on trying to educate the population and holding the patients responsible for their disease ${ }^{(4)}$.

The boom in the sanatoria took place after the discovery of Koch's bacillus in 1882 . The treatment was based on pure air, abundant food and rest, although the patient could exercise moderately ${ }^{(1-2)}$. The patients were separated by gender and lived under certain standards and restrictions: to give an example, alcohol and tobacco consumption and leaves were prohibited and visits were controlled(1). The patients were offered distraction through different activities and illiterate patients got education(3)

The sanatorium was the place were the patients gained awareness of their difference and felt part of a group with its own identity ${ }^{(6,8)}$. Once cured, some patients remained and even worked at the sanatorium(8-9). This answer was related to the idea that the cured continued living in the mountains out of fear of relapses and with the threatening stigma of the disease $^{(8)}$. Reclusion in the sanatoria allowed the doctors and nurses to educate the patients and maintain contro over their lives ${ }^{(10)}$.

In Spain, the first sanatorium was located in the Busot spa hotel, inaugurated in Alicante in 1897 and destined for the upper social class ${ }^{(1)}$. The first sanatorium in the country that continued was inaugurated in 1911 in Terrassa(2). The Sanatorio del Espíritu Santo was inaugurated near Barcelona in 1917 and, within a care philosophy based on Christian practice, its goals was to attend to poor tuberculosis patients in the terminal phase of the disease(11).

The expansion of the sanatoria happened under Franco's regimen (1939-1975), when the sanatorium treatment was already declining due to the new advances in the field of medicine ${ }^{(2)}$, better professional care delivery, the economic recovery after the Spanish Civil War (1936-1939) and World War II and, finally, as a result of the workers' better work and family conditions $^{(1)}$.

In Spain, at the end of the $19^{\text {th }}$ and the start of the $20^{\text {th }}$ century, the nursing care offered by religious orders was based on the reestablishment of health and the need for medicine to create an auxiliary profile for the physicians ${ }^{(12)}$. This could be observed in the nurses' role in the sanatoria(13).

This study departs from the idea that the nursing professionals' work in the sanatoria was never socially acknowledged because the nurses worked in a context in which Tb was a stigma(9-10). In Spain, some of the studies about the care developed in the sanatoria adopt a medical perspective ${ }^{(11)}$, or do not specify the nursing care because they have neither sufficient documents nor live testimonies to analyze the professional role(14-17). Recent studies have analyzed the role of nurses in the sanatorium in Kent, England(9) and in Westwood, Australia(10)

In this study, the objectives are to identify the nursing professionals' profile and work conditions and to describe the nursing care at the Sanatorio del Espíritu Santo, located near Barcelona, Spain, between 1943 and 1975. This study is justified because it demonstrates the contributions of nursing care, which were fundamental for the recovery of tuberculosis patients and for monitoring with a view to a dignified death. In addition, as Tb was experienced similarly in Western countries and remains a stigmatized illness until today ${ }^{(18)}$, this study permits comparisons.

\section{Methods}

A historical study was undertaken based on oral and documentary sources(19-20). Oral sources; the participants were intentionally selected. The selection was based on convenience criteria and the snowball 
technique(21). A nurse from the current Hospital, who had been working as an auxiliary during the 1970's (A1), was the participant who originated the chain sampling; the initial contact with her was by telephone. The selection criteria were that participants had worked as nurses or nursing aides at the Sanatorio del Espíritu Santo between 1943 and 1975, independently of whether they held a nursing degree or not and if they were secular or religious. People who did not comply with the selection criteria and without excellent physical conditions to receive visits or move around and/ or mental conditions, like knowing how to locate the memories in the social and political context, knowing how to express themselves clearly and reflecting on their experiences(20). Nevertheless, in view of the relevance of the oral history(20), in the course of the study and due to difficulties to fin live testimonies who had worked at the sanatorium before 1950, the relative of a deceased nurse who had worked at the sanatorium during the Spanish post-war, between 1943 and 1945, were excluded.

The contact with the participants happened in two phases, between 2008 and 2010. In the first phase, between November 2008 and June 2009, three women were interviewed who served as nursing aides (A1-A3) and two religious nurses (E1-E2). In the second phase, and thanks to the information the professional responsible for the User Care Service of the Sanatorium had provided, one relative of the nurse who had worked in the post-war period was contacted (F1)

Documentary sources: Documents were consulted from the Archivo Histórico del Hospital del Espíritu Santo and the Archivo de la Escuela Universitaria de Enfermería de Barcelona. The selection criteria were that the documents were clearly readable, were signed and/ or contained a stamp for identification. These documents were: the internal regimen for the patients from $1946^{(22)}$, the nursing transcripts from the Universidad de Barcelona between 1943 and $1945^{(23)}$ and the Cooperation Agreement between the Hermanas Hospitalarias de la Santa Cruz and the del Hospital-Sanatorio del Espíritu Santo, closed on October $15^{\text {th }} 1974^{(24)}$. These documents were selected because they inform about the nursing activities in the Sanatorium and verify whether the nursing staff held an official degree.

The data collection instruments were semistructured interviews with the participants and documentary analysis. In four cases, the interviews were held at the participants' homes and, in two cases, in a private room in the current facilities of the new
Hospital, formerly the Sanatorium, taking between one hour and one hour and a half; the interviews were tape-recorded for further transcription. The participants signed an informed consent form and received a code to preserve their identity. The analysis of the historical documents happened in parallel with the interviews. The triangulation of the information sources $^{(19,21)}$ permitted guaranteeing the quality criteria of the research: credibility, transferability and dependence(19).

A license was signed with the Human Resources Department of the Sanatorium and the nursing management authorized the development of the study. Ethical clearance was sought from the center.

The data analysis on the information obtained from the interviews and historical documents were organized in codes and categories(19). The analytic categories were: caregiving staff, work conditions and nursing care. The category caregiving staff included the following codes: Hijas de la Caridad de San Vicente de Paúl, secular staff, Hermanas Hospitalarias de la Santa Cruz, internal organization and degree. The category work conditions included the codes: economic resources, material resources, structural conditions, preventive measures, work hours, economic remuneration and low-skilled work. Finally, the category nursing care was analyzed based on the human needs codes described by Virginia Henderson(25): breathing normally, eating and drinking appropriately, moving and maintaining an appropriate posture, sleeping and resting, selecting appropriate clothing for grooming, maintaining one's body temperature within normal limits, maintaining one's bodily hygiene and skin integrity, communicating with other people. Besides, the following codes were included in the nursing care category, which emerged from the participants' discourse: distracting and spiritual care, monitoring and administering medical treatment. This structure was adopted for the sake of an easier understanding and order in the results during the elaboration of the manuscript. The results were discussed with the advisor of the doctoral dissertation.

\section{Results}

\section{Profile of the nursing staff}

Different religious institutions delivered care to the tuberculosis patients at the Sanatorio del Espíritu Santo. Between 1943 and 1945, the Hijas de la Caridad de San 
Vicente de Paúl worked as nurses together with secular staff. Evidence was found of only one man who worked as nursing staff and held the degree(23). In addition, there were secular women working as nurses; some held an official degree and others did not(23). One woman and the man, both nursing staff, had been Tb patients at the sanatorium (F1).

In 1945, the Hijas de la Caridad were replaced by the Hermanas Hospitalarias de la Santa Cruz. The Hermanas Hospitalarias were the sole nurses at the Sanatorium between 1945 and 1975. The nuns worked with women hired as nursing aides, with voluntary staff and with women working in the Social Service, which was compulsory for most of the Spanish population under Franco's regimen (E1-E2, A1-A3). In that period, the responsible for nursing care was the local Mother Superior, who served as the nursing supervisor, was in change of selecting the nurses' auxiliary staff and watched over the community's wellbeing (E1-E2).

To be allowed to work at the Sanatorium, one should not hold a degree, but be willing to take care of poor tuberculosis patients (A1). Tb was stigmatized, people were afraid of the disease and it was difficult to find people willing to work at that center (E2, A1-A3). As from 1974, the Sanatorium required the nuns to hold the degree of registered nurse and, for the aides, the degree of auxiliary nurse(24).

\section{Work conditions of care staff between 1943 and 1975}

The nursing staff worked under precarious economic conditions, reflected in the lack of material resources and deficient structural conditions at the center: There was no heating, the Sanatorium had no money, we were very poor. The windows did not close well and, when it rained, there was water coming into the rooms (E1). The Sisters recycled the material they needed and managed the purchases of fundamental material (E2). Syringes, needles and gauze were washed, disinfected and sterilized (E1-E2, A1-A3).

To fund the Sanatorium's activities, the Sisters also collaborated to collect money through beneficial actions, as one nurse describes: Many patients were very poor and we tried to get them resources. Sometimes, we put tills next to the cash registers of the neighborhood shops and soon went to pick them up (E1).

The nursing staff worked without measures to prevent the $\mathrm{Tb}$, despite direct contact with the patients (F1, E2, A3). The work hours were intense, the nuns worked each day and the Mother Superior determined the shift distribution. The nursing aides got leave one day of the week. Initially, the nuns charged a symbolic salary, which improved over time and, as one nurse mentions: we did not charge much in economic terms. At that time, they paid us very poorly in pesetas. But later, they put us on the payroll and social security records, according to the professional category (E1).

The nursing activities were hardly systemized and nursing records did not exist: so there were no nursing records, it was just written down in the patient's history what he had to take and what you had to give him. The doctor wrote down what he had seen that day (A2). The absence of specialization and limited staff encouraged teamwork (E1-E2, A1-A3). The nurse's work was relegated to the physician's figure and was expected to fulfill his $\operatorname{orders}^{(22)}$.

\section{Nursing care at the Sanatorium}

Breathing normally: The patients spent rest periods on hammocks in a gallery, four times per day (after breakfast, after lunch, before dinner and before going to sleep), under the nurses' supervision. Some patients had their own rest chair. The rest periods took between $1 \mathrm{~h} 30$ minutes and $2 \mathrm{~h}$. During the rest periods, the women were allowed to work and talk silently. After lunch, the patients were expected to remain totally silent and no work was allowed. Only patients who had improved and on doctors' orders could do manual work in the siesta room. Silence was aimed at not tiring the tuberculosis patients ${ }^{(22)}$. The patients were not allowed to smoke inside the building, but the men were allowed to during the external excursions ${ }^{(22)}$.

Eating and drinking appropriately: During the postwar period, food was scarce but, at the Sanatorium, the economic situation was better than many families in economic difficulties. Therefore, some people in delicate health were hospitalized in the Sanatorium although they did not suffer from Tb. The food they received allowed them to get reestablished (F1).

As from 1945, the Hermanas Hospitalarias de la Santa Cruz were responsible for buying the food needed for the patients. The Mother Superior got up at four o'clock in the morning to visit a wholesale market in Barcelona and buy fresh foods: fruits, vegetables, greens. The Mother used a car with a driver (E1-E2). The Sister who served as the cook decided what to buy (E1).

The Sanatorium had an animal farm with chicken, pigs and ducks. The nuns were responsible for controlling the farm with the help of the hortelanos, as one nurse describes: We aimed to feed the ill as much as we 
could in those days, because there were no extraordinary things.

Sometimes we killed a pig from the farm, so we'd have at least meat for the patients (E1). The tuberculosis patients did not get any kind of special diet: most of the patients were young and hungry (E1).

The main food for breakfast and snacks was milk, coffee, bread and butter or olive oil and cookies. For lunch and dinner, the diet mainly included meat, vegetables and greens (E1, A1). Sometimes, the patients did not want to eat because they had no appetite or because they did not like the food; so the nurses tried to satisfy their needs by preparing something different or that could make them feel well (A2, E2). There were also people who donated food to the Sanatorium (E1).

Moving around and maintaining an appropriate posture: The patients went for short walks in the Sanatorium gardens, but were prohibited to walk around in other places(22). The Sisters-nurses accompanied and guarded them. Bedridden patients were not allowed to get up if rest had been prescribed to them (E1).

Sleeping and resting: The patients shared the rooms and were separated by gender in different pavilions. Each room held at least eight patients, arranged in individual beds. Each day, the rest period was followed by the siesta(22). At night, the nursing aides were in charge of the patients and one Sister oversaw their wellbeing in the two pavilions of the Sanatorium (E1-E2, A1).

Selecting appropriate clothing for grooming: The Sisters controlled the patients' clothing and were responsible for the laundry service. One nun, with the help of aides, washed, ironed and sewed the clothes (A1). The clothes were marked for the sake of identification: the patients' clothing was numbered so that each would now which clothes were his (E1). If the patient died at the Sanatorium and did not have and family, his clothing was washed and reused for other poor patients. If it could not be used, it was cast away or burned. Sometimes, some relatives of the Sisters donated surplus or torn pieces of fabric. The nuns used these to make sheets and towels for the patients to use (E1).

Keeping the body temperature within normal limits: each patient had a personal thermometer and two overalls. The nurse checked that each patient had the material and did routine tests ${ }^{(22)}$.

Maintaining bodily hygiene and skin integrity: The patients had two spittoon containers at their disposal, one of which was a pocket model and each container was individual(22). The patients were expected to take "cleaning baths" as many times as needed; they were expected to bathe at least every two weeks and not less than once per month. Personal hygiene was done at seven o'clock in the morning. They were also expected to wash their hands before sitting down to eat and perform oral hygiene after meals. They should remain composed at the table, eating slowly and fully mastigating the food.

The independent patients did their own hygiene, while the nurse-Sisters, with the help of the aides, washed the bedridden patients. Sometimes, due to different causes, such as poverty, weakness and the patients' sloppiness, it was difficult to make them do their hygiene: Sometimes we discussed for the patients to wash. There were some patients from the harbors and if you had to wash them they did not want to and in the end you had to get angry (E1). Another aspect that should be highlighted is that the nurses were always concerned with maintaining the Sanatorium in order and clean (A3).

Communicating with other people: The patients had to respect one another, be loving and kind and respect the Sanatorium staff. They were expected to accept the standards and neither curse nor use coarse language ${ }^{(22)}$. They had to be grateful to the religious community and the physicians. Since 1945, the nurse-Sisters were in charge of supervising the patients' compliance with these rules of morals and decency (E1).

Distracting and spiritual care: Distraction activities used to be religious celebrations that instilled the patients with Christian morality, besides being leisure acts. Each day in the morning, the patients attended the Holy Mass, accompanied by the Sisters, although they were not obliged to attend and pray in the afternoon. Other distraction activities also took place at the Sanatorium: the women sewed and the men had a workshop for manual work (E1).

Companionship: The Sisters attempted to make the patients who were alone participate in the traditional religious feasts and feel accompanied. As one nurse expressed: I have always enjoyed taking care of all facets of the person, that is, the illness and the environment, which was sometimes worse than the disease they suffered from (E2). The Sisters also assisted the dying and their family and attempted to make sure they received the final blessing.

Administration of medical treatment: The Sisters were responsible for administering the treatment the doctor prescribed and keep him informed about the patient's health condition(21). 


\section{Discussion}

As regards the nursing staff's profile, the presence of nuns in sanatoria was common in Spain ${ }^{(14-17)}$. They worked at hospitals and sanatoria in the course of the $19^{\text {th }}$ and part of the $20^{\text {th }}$ century, until these stopped being charities ${ }^{(12)}$. Therefore, there was no lack of nurses at the sanatoria in Spain, which was the case in other countries like Australia, where the sanatoria were located in isolated geographical regions with access problems, besides being places identified with death; therefore, for nurses to accept working at these centers, they had to be offered incentives ${ }^{(10)}$.

The cooperation of secular staff with the nuns was common at the Spanish sanatoria ${ }^{(14-17)}$. At the Sanatorio del Espíritu Santo, some of the workers were former tuberculosis patients and then worked as nursing staff or servants. This fact also happened at other sanatoria in Argentina ${ }^{(8)}$ and England ${ }^{(9)}$. At the Sanatorio del Montseny ${ }^{(14)}$, some men worked as nursing aides together with the nuns to take care of male patients. At the Sanatorio del Espíritu Santo, there was one man working as a nurse.

The nurse-Sisters at the Sanatorio del Espírtu Santo watched over the center's proper functioning through the compliance with the patients' internal regimen. The Sisters' relation with the Junta de Asociación del Sanatorio determined the continuity of the Hijas de la Caridad, who were replaced by the Hermanas Hospitalarias de la Santa Cruz in $1945^{(11)}$.

At some sanatoria near Barcelona, the nurseSisters faced difficulties to control the center's proper internal functioning, due to some patients' conflicting behavior $^{(14-15)}$ or the board's non-compliance with agreements closed with the nuns ${ }^{(14)}$. As a result of this fact, at some sanatoria, the Sisters decided to leave the center ${ }^{(14-15)}$.

The nurses' work conditions were hostile because the sanatoria were identified as monotonous places of demoralizations and preludes of death ${ }^{(10)}$. In Barcelona, most of the secular nurses did not want to work at centers far from the city, the type of patient did not attract them and the wages were lower than what they could gain at other hospitals affiliated with the Social Security network in the 1970 's(14).

In England ${ }^{(9)}$, the nurses' activities were similar to those of the nurses at the Sanatorio del Espíritu Santo: they controlled the need for food by controlling the diet, the patients used the dishes, did not share food and receiving gifts in the form of food was prohibited; they maintained the hygiene through sputum control and its collection in the spittoon containers, took care of the drains and cured any wounds. The nurses also performed prevention and education activities and organized activities to distract the ill(9-10). They represented the patients' only direct contact in their daily life with other people ${ }^{(10)}$. Nevertheless, no prestige is attached to the care centered on the patients' physical and psychological needs because it is not associated with activities of cooperation with the medical profession ${ }^{(10)}$.

After Waskman discovered streptomycin in 1943 and Fleming discovered penicillin in 1945, chemotherapeutic treatment was the permanent solution in the fight against primary $\mathrm{Tb}^{(1)}$. Since then, $\mathrm{Tb}$ turned into a curable disease that could stop being stigmatized(5). Today, however, the disease is still associated with the symptoms of social misery: hunger, lack of resources for one's own survival and excesses such as alcohol or drugs consumption ${ }^{(5,18)}$. The ideas about contamination and relapses in Tb provoke mistrust regarding the possibility of recovery ${ }^{(5)}$. The prejudice related to Tb hampers and delays the diagnosis of the disease, due to the shame the patients themselves feel(18).

The study limitations are related to the difficulties to find live testimonies who had worked at the Sanatorio del Espíritu Santo before 1950 Nevertheless, information was collected from other sources. As regards the instruments, the consultation of written documents permitted contrasting the participants' information.

These research results permit showing the work of the nursing staff and provide knowledge. For the sake of professional practice, they offer the possibility to improve the feeling of belonging to the group, selfconcept and self-esteem.

\section{Conclusions}

Between 1943 and 1975, the profile of the nursing staff at the Sanatorium mainly consisted of nuns who worked together with secular professionals. In 19431945, some women and one man held a nursing degree, some of whom were former tuberculosis patients. The nursing head was a nun at all times. The nursing degree was required as from 1974. The economic and material resources were precarious but improved over time. The work journeys were intense, the nuns' economic remuneration was symbolic and no preventive measures were implemented. 
The care delivery was focused on attending to the basic physiological needs and accompanying the dying at the time of death, always complying with doctor's orders in a selfless manner. The nurses offered emotional and spiritual support which in the case of the tuberculosis patients was particularly relevant, as this disease was stigmatized and separated them from society. The nuns practiced other functions related to administration and human, economic and material resource management. As from 1946, the nuns took control over the internal functioning and the patients' morality at the Sanatorium, overseeing compliance with the internal regimen.

The work the nursing staff performed at the Sanatorio del Espíritu Santo has not been socially acknowledged, as it was mainly performed by women, who in addition worked in a stigmatized context. This study permits showing nursing's contribution to care, provides written records and contributes to the consolidation of the discipline.

\section{References}

1. Báguena MJ. La tuberculosis y su historia. Barcelona: Fundación Uriach 1838; 1992. 119 p.

2. Sauret J. La cura sanatorial de la tuberculosis. Enferm Emerg. 2001;3(4):199-205.

3. Blinn V. Blood, Coughs and Fever: Tuberculosis and Working Class of Buenos Aires, Argentina, 18851915. The Society for the Social History of Medicine. $1999 ; 2(1): 73-100$.

4. Molero J. La muerte blanca a examen: nuevas tendencias en la historiografía de la tuberculosis. DYNAMIS. 1991;11:345-59.

5. Porto A. Representações sociais da tuberculose: estigma e preconceito. Rev. Saúde Pública 2007;41 (Supl 1):43-9.

6. Robbins JM. Class Struggle in the Tubercular World: Nurses, Patients, and Physicians, 1903-1915. Butlletin of the History of Medicine. 1997;71:412-34.

7. Gofman E. Estigma: La identidad deteriorada. 2a.ed. Buenos Aires: Amorrortu; 2008. 183 p.

8. Carbonetti A. Discurso y práctica en los sanatorios para tuberculosos en la provincia de Córdoba 19101947. Asclepio.2008;60(2):167-86.

9. Kirby S. Sputum and the Scent of Walflowers: Nursing in Tuberculosis Sanatoria 1920-1970. Soc History Med.2010;23(3):602-20.

10. Kirby $S$, Madsen W. Institutionalised isolation: tuberculosis nursing at Westwood Sanatorium,
Queensland, Australia 1919-1955. Nurs Inquiry. 2009;16(2):122-32.

11. Cid F, Gorina N, Sánchez J. L' Hospital de I'Esperit Sant. Un exemple de l'evolució asistencial a Catalunya. Santa Coloma de Gramanet: Fundació Hospital de I'Esperit Sant; 1993. 252 p.

12. Dominguez-Alcón C. La infermeria a Catalunya. Barcelona: Rol; 1981. 206 p.

13. González M. La enfermera en la lucha antituberculosa. Una obra de Leopoldo Cortejoso. Index Enferm. [Internet]. 2003 [acesso 01 mar 2013].;12(42). Disponível em: http://www.index-f.com/index-enfermeria/42revista/42 sumario.php

14. Cateura X. Estances de Febre. El Sanatori del Montsey. Monografies del Montsey. 2010; (25).

15. Miret P. Història de la "Ciutat Sanatorial de Terrassa" (1952-1986). Gimbernat. 2009;51:225-50.

16. Solorzano M. La apasionante historia de la medicina y la enfermería en Tolosa (Guipúzcoa). Enfermería avanza [Internet]. 2009 [acesso 7 dez 2012]. Disponível em: http://enfeps.blogspot.com.es/2009/04/la-apasionantehistoria-de-la-medicina.html

17. Solorzano M. Historia y Antecedentes del Hospital de Amara. Eskonews \& Media [Internet]. Oct 2003 [acesso 15 dez 2012]; (27):24-31. Disponível em: http://www.euskonews.com/0227zbk/ gaia22702es.html

18. Hino P, Ferreira RF, Bertolozzi MR, Villa TCS, Egry EY. Family health team knowledge concerning the health needs of people with tuberculosis. Rev. Latino-Am. Enfermagem. 2012;20(1):44-51.

19. Lincoln YS, Guba ES. Naturalistic Inquiry. Newbury Park, CA: Sage; 1985. 416 p.

20. Folguera P. Cómo se hace historia oral. Salamanca: Eudema; 1994. 96 p.

21. Gerrish K, Lacey A.Investigación en enfermería. Madrid: McGraw-Hill Interamericana de España; 2008. 550 p.

22. Barcelona (ES). Archivo Histórico del Hospital del Espíritu Santo. Reglamento de régimen interior de los enfermos, 1946. Legajo 4, no36e.

23. Barcelona (ES). Universidad de Barcelona. Archivo de la Escuela Universitaria de Enfermería de la Universidad de Barcelona. Expedientes académicos, sin catalogar.

24. Barcelona (ES). Archivo Histórico del Hospital del Espíritu Santo. Convenio de las Hermanas Hospitalarias de la Santa Cruz con la Fundación del HospitalSanatorio del Espíritu Santo, 15 de octubre de 1974. Legajo 5, n०60. 
25. Henderson V. La naturaleza de la enfermería.

Una definición y sus repercusiones en la práctica, la investigación y la educación: reflexiones 25 años después.

Madrid: McGraw-Hill Interamericana; 1994. 115 p. 